\title{
LA INVESTIGACIÓN EN LA PRÁCTICA DEL TRABAJO SOCIAL. LA EXPERIENCIA COMO FUENTE DE CONOCIMIENTOS.
}

\section{INGER HELEN ERSTAD}

Center of Child Welfare Research. Tromso. Noruega.

Traducción de: Angélica Majos.

\section{INTRODUCCIÓN.}

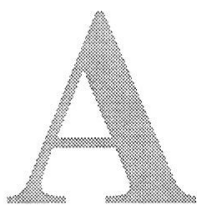

nte todo, quiero dar las gracias por haber sido invitada a participar en esta conferencia. Supone para mí un reto, y una experiencia muy interesante, poder colaborar y aportar pensamientos sobre el Trabajo Social con la experiencia de Noruega como marco de referencia, mientras la vuestra es la española.

El tema de la conferencia es la violencia y quiero trasmitir la experiencia del Trabajo Social en Noruega. El tiempo del que dispongo no me permite entrar en detalles en cuanto al pensamiento profesional, porque el problema es complejo y no existe una visión única de cómo tratarlo. Por ello, quiero hacer referencia a un proyecto que considero interesante, se llama "la violencia silenciosa", con él se ha trabajado la violencia en la familia enfocada a la situación del niño.

En segundo lugar, quiero hacer referencia a la investigación en la práctica del Trabajo Social, según la tradición de la Filosofía sobre la práctica. Como introducción, haré una referencia a la tradición de los conocimientos y la relación existente entre la experiencia práctica y el conocimiento teórico. Posteriormente, presentaré las experiencias del proyecto llamado "la violencia silenciosa" y, para terminar, plantearé una discusión sobre cómo se podría haber profundizado en estas experiencias mediante las sugerencias de la Filosofía sobre la práctica.

\section{CONOCIMIENTO TEÓRICO Y EXPERIENCIA PRÁCTICA.}

En nuestra sociedad se hace referencia al conocimiento teórico, basado en los conocimientos de la investigación, como única base legítima de conocimientos para la ejecución profesional (Molander 1993). 
Los modelos teóricos y sus métodos son la referencia para la actuación en la práctica. Esta visión se hace patente también en la enseñanza del Trabajo Social.

Dar tal importancia a la teoría plantea el peligro de que el profesional observe la situación únicamente con las "gafas de la teoría" y que no se aperciba de los detalles o lo "especial" de la situación en sí. Este conocimiento teórico debe ser trabajado a través de la experiencia y la reflexión sobre la situación, para, de este modo, poder utilizarlo bien y de una manera flexible.

Con referencia a Wittgenstein, se puede afirmar que el contenido de las palabras se hace más profundo con la experiencia. Es en la actuación cuando el profesional enseña lo que ha entendido. En la actuación, el profesional se encuentra con acontecimientos que las normas generales no pueden captar. "La teoría no es suficiente para describir un práctica profesional, también se necesitan ejemplos. La teoría deja las puertas de atrás abiertas y la práctica tiene que hablar por sí misma."

Con la reflexión a partir de la experiencia propia, se puede mostrar un camino a otra fuente de conocimientos, que podríamos llamar conocimientos basados en la experiencia o conocimiento práctico, relacionado con consideraciones, juicios y actuaciones en situaciones concretas. Este conocimiento, en realidad, forma parte del contenido profesional, pero se utiliza en gran medida a nivel verbal e individual y forma parte de una actuación conocida a nivel profesional que, generalmente, es aceptada como válida.

El nuevo profesional es conducido, más o menos sistemáticamente, hacia esta tradición o es introducido en la práctica a la manera de pensar de la institución y sus formas de trabajar.

Muy pocas veces se advierte, se analiza o se escribe sobre este conocimiento basado en la experiencia. Es un conocimiento que puede aportar un contenido para el desarrollo de la práctica profesional, pero que se mantiene invisible para la producción de los conocimientos. Manteniéndose invisible no posibilita que sea objeto de reflexión crítica. ¿Cómo se caracteriza la sabiduría, qué es lo mitificado o falta de conocimientos?

El conocimiento práctico se visualiza en forma de competencia de juicio en situaciones concretas, donde creamos unidades de comprensión, basadas en una serie de experiencias anteriores de situaciones parecidas (Janik,1996). La forma del conocimiento se caracteriza por el juicio o la capacidad de hacer distinciones importantes. A través del conocimiento práctico, se desarrolla la capacidad de hacer un juicio sobre situaciones específicas que se igualan, pero que no son idénticas, 
y observar semejanzas en lo que a primera vista parece diferente. De este modo, es la situación que, al contrario del conocimiento teórico establecido, es la unidad de comprensión significativa. Basándonos en la comprensión que se desarrolla por esta vía, seremos capaces de hacer un juicio de la situación en el momento que aparece. Desarrollamos familiaridad con la situación y habilidad en la práctica profesional. La habilidad para hacer este tipo de conexiones y establecer observaciones análogas es un conocimiento que también se puede describir como sabiduría práctica.

En la práctica "sabia", las consideraciones éticas vienen incorporadas. Ello lleva a comprender el concepto "Phrónêsis de Aristóteles"1. Un concepto que apunta a un análisis de los valores como punto de partida de una actuación -para decidir cuál es la actuación correcta en una situación determinada-. Phrónêsis enfoca en lo que es variable y pendiente de un contexto y requiere una acción cambiante entre lo general y lo específico, consideración, juicio y determinación en un momento dado.

Existe necesidad de crear un equilibrio mejor entre el conocimiento teórico y práctico. Un conocimiento basado en la experiencia, de modo que éste se utilice de una manera más sistemática para que sea fuente de comprensión y desarrollo de conocimientos. El conocimiento práctico se expresa a través de la actuación y tiene una forma lógica relacionada con la misma práctica profesional. De este modo, se puede decir que es una forma de conocimiento que no puede ser traducido directamente a un conocimiento teórico.

El conocimiento práctico tiene sus propias raíces de conocimientos teóricos, heredadas de Aristóteles, y como tal debe ser comprendido. Ello no quiere decir que se deban observar el conocimiento teórico y el práctico como dos unidades totalmente separadas, sino más bien como fuentes de conocimiento que se complementan (Molander, 1993). Un trabajo sistemático sobre los conocimientos de la práctica es un reto metodológico importante para asegurar la calidad de trabajo de los profesionales.

El camino es de reflexión sistemática sobre situaciones concretas, situaciones donde la habilidad y la comprensión es retada y probada. Las situaciones difíciles y los dilemas en el trabajo son especialmente indicados para observar la competencia de juicio y lo singular en la ejecución de la tarea, haciéndose ver, de esta manera, que la actuación profesional se abre a un dialogo con el exterior, con el espacio público.

A continuación, observaremos cómo en el proyecto "La violencia silenciosa" reflexiono sobre la experiencia y la tramitación de ella, ba- 
sándome en el informe del mismo. También se ha profundizado sobre algunos aspectos dialogando con dos personas claves en el proyecto.

\section{EL PROYECTO "LA VIOLENCIA SILENCIOSA".}

El proyecto "La violencia silenciosa" está relacionado con el dispositivo de urgencias de menores en Oslo. Este dispositivo colabora con la policía y, entre otras cosas, interviene de emergencia, visitando familias donde se ha avisado de que se han producido gritos, insultos y demás desordenes públicos, para prestar una ayuda inmediata. El proyecto fue elaborado para poder ofrecer una ayuda específica y de seguimiento a aquellas familias donde surgía la violencia. Se promovía la creación de este dispositivo porque los entes que trataban con las familias no se veían preparados para afrontar los hechos, ya que éstas no daban importancia a lo acontecido o no expresaban necesidad de ser ayudadas.

Los retos y metas del proyecto han sido los de encontrar maneras de establecer medios para contactar con las familias y enfatizar sobre la situación del niño, ayudando a éstas a buscar otros modos de comunicación y de resolución de los conflictos. Se observó la necesidad de situar a los agentes de ayuda cerca y accesibles a las familias, y que fueran activos en visitarlas.

El proyecto duró un año y tenía 2,5 puestos profesionales a su disposición. Trabajaron activamente con 40 familias, aunque estuvieron en contacto con muchas más. En general, se ncontraron con hombres que ejercitaban la violencia sobre sus mujeres, lo que está en concordancia con otras investigaciones sobre la violencia, o dicho de otra manera: papá ejercitaba la violencia sobre mamá. En un $70 \%$ de los casos, los niños eran observadores de esta violencia. Algunos de ellos también habían sido víctimas de ella. Hablando de violencia, incluimos la física, en forma de azotes, patadas o uso de objetos, y la psíquica, en forma de amenazas o desconsideraciones, etc.

\section{PONER NOMBRE A LO DOLOROSO.}

Véanse dos citas que pueden ilustrarnos la vivencia de los niños en la violencia doméstica:

"Oí que mamá gritaba. No me atrevía a entrar en el comedor. Pensé ¿quién me va a acompañar mañana al colegio si mamá había muerto?" (niño de 6 años).

"Ahora pega a mamá, tengo miedo. Miedo de que ella va 


\section{a llorar" (niña de 5 años).}

Éstas son palabras que nos tocan el corazón a todos. En el informe, los profesionales expresan lo siguiente: "en el encuentro con las víctimas, frecuentemente madre e hijos, y el padre, que ha actuado con violencia, nosotros, como agentes de ayuda, nos enfrentamos a muchos retos. Tenemos que controlar nuestras propias reacciones para ser capaces de encontrarnos con estas familias y afrontar el tema de la violencia de manera que se pueda hablar de ella... Nuestra experiencia es que muchos niños sienten alivio cuando se puede romper el tabú y se habla con ellos, con mamá y papá sobre este tema".

Dialogar y profundizar en la comprensión de los miembros de la familia, de la situación, es el fundamento profesional del proyecto (Anderson y Goolishian, 1992). Se han elaborado las metas de trabajo, pero hace falta gran flexibilidad para salir al encuentro con cada familia, como esta familia en concreto.

La fase más vulnerable es la que trata de establecer contacto con la familia. Una acción violenta puede llevar a una reacción de crisis y, por ello, es importante establecer contacto con la familia de inmediato, después del suceso violento. Aquí la referencia teórica es la teoría de las crisis (Cullberg, 1991). La crisis, como una fase abierta, contiene tanto peligro como posibilidades, por ello, no andamos con lista de espera: cuando se dirigen a nosotros, tomamos contacto por teléfono de inmediato.

Aunque las familias acepten el encuentro con los agentes de ayuda, existe mucha inseguridad cuando se reúnen con ellos, lo que se manifiesta en expresiones como "hoy no puede ser". La familia desea aplazar el encuentro o anularlo cuando se acerca el día de la reunión. La actitud ante esta negativa es de aceptación, ya que puede haber situaciones donde es necesario anular el encuentro. Es importante que la familia misma pueda decidir fecha y lugar. La experiencia nos ha demostrado que esta actitud es la conveniente, ya que la familia suele decidirse por la primera reunión con los agentes profesionales de ayuda. Las familias tienen la sensación de tomar parte en las premisas de la colaboración.

\section{UN EJEMPLO.}

El hecho de que la familia consienta el contacto con los agentes quiere decir que acepta el hecho de que la violencia es un tema a tratar, pero de ahí a que se consiga un diálogo abierto sobre el tema es otra cosa. En el proyecto se ha considerado importante hablar con los niños y la razón por la que vienen. Un ejemplo: 
En un primer encuentro, con una madre y sus tres hijos, le preguntamos, con los niños presentes, si ella había explicado quiénes éramos y por qué veníamos. Ella movía la cabeza indicando que no. Le preguntamos si ella pensaba decirles algo sobre ello. Ella movió otra vez la cabeza insistiendo que no y dijo que tenía miedo de lo que ellos podrían contar a otros. Preguntamos, entonces, si nosotros podíamos explicarles, con tacto, el porqué de nuestra visita. Le pareció bien, pero mostraba gran preocupación por lo que pudiéramos decir. Contamos a los niños que mamá y papá tenían ganas de hablar con nosotros y ése era el motivo por el que habíamos venido. Dijimos que sabíamos que ellos tenían muchas cosas buenas que compartir, pero que no siempre había buen ambiente cuando estaban juntos y que a veces empezaban a discutir. Dijimos que los padres querían terminar con las discusiones y eso era de lo que querían hablar con nosotros.

Como podemos observar, el acercamiento es muy paulatino, a la vez que dicen cuál es su juicio de la situación, es decir, que es importante para los niños poner palabras del porqué han venido. Se enfoca hacia los niños. Mediante sugerencias suaves, dan a la madre la posibilidad de hablar con ellos. Cuando la madre quiere evitarlo, los agentes de ayuda piden permiso para ser ellos quienes cuenten por qué están allí. Se dan cuenta de que la madre se encuentra insegura de lo que van a hablar, pero ellos, los agentes de ayuda, están en su juicio. Es su manera de enseñar una actitud abierta donde incluyen a todos, también a los niños con su perspectiva.

Observamos que hablan de lo positivo, que saben o suponen, que existe en la familia y también saben que de vez en cuando discuten. Aunque no sabemos cómo se utiliza la violencia en esta familia, podríamos decir que la característica de llamar a la situación de violencia como una "discusión" es evasiva o, puede ser, este concepto es un denominador común que todos reconocen, aunque se le puede dar un significado u otro según la situación.

En el informe, se explicita que la madre se encontraba aliviada después de la visita y que le parecía bien lo que se había comentado. Los niños parecían entender el porqué de la visita de los profesionales y empezaban a estar más ocupados con sus juegos y otras cosas propias de los niños. El ejemplo enseña cómo han realizado un acercamiento cuidadoso, a los miembros de una familia, al tema de la violencia.

\section{FLEXIBILIDAD EN EL TRABAJO.}

En el proyecto se busca una perspectiva global sobre la familia y se da la misma importancia a encontrarse con una víctima de la violencia 
como con el que la ejecuta. A la vez, se pone énfasis en que las entrevistas no sean vivenciadas como otro ataque a la víctima. Por ello, hay una variación en la composición de la presencia de los miembros de la familia en las entrevistas, o sea, de forma individual o juntos. Intentan encontrarse con la familia en una ambiente de actitudes exentas de juicios y experimentan que la confianza aumenta conforme manifiestan que quien ejerce la violencia es responsable de sus actos.

Han experimentado que la manera de hacer las preguntas puede ser decisiva para lo que se espera sea la respuesta. Es fácil preguntar por qué cuando algo no se entiende, pero este tipo de preguntas pueden desenfocar la situación real. También se puede sentir como un "ataque" si estamos buscando faltas y deficiencias en la persona. Las preguntas deben dirigirse de manera que puedan propiciar el diálogo y ampliar la comprensión sobre lo que realmente ha sucedido.

Una manera sutil de dialogar, de manera que fluya ligeramente, incluyendo algunas cosas insignificativas, como el gato que entró en la habitación o el estado del tiempo, para que todos los miembros de la familia puedan entrar en la charla y la familia pueda enseñar que existe otras cosas en su vida familiar, no únicamente la violencia.

Esta manera neutral de mantener la comunicación se puede utilizar más adelante en el proceso para crear pequeños huecos de respiro cuando el tema de la violencia se presente como demasiado pesado y amenazador.

Se enfoca el tema, especialmente, hacia los niños dentro de la familia. Ello conlleva también un enfoque hacia el rol de los padres. Si papá tiene que aceptar la responsabilidad por sus actos violentos, mamá tiene la responsabilidad que conlleva la situación de seguir viviendo en una situación de malos tratos donde los niños, su cuidado y su desarrollo también es su responsabilidad. La responsabilidad de la vida y desarrollo de los hijos es una palabra clave.

La experiencia nos enseña que los padres deben sentir una gran confianza antes de que se atrevan a hablar de las vivencias de los niños. Ello se encuentra de fondo, como un tema doloroso, que conlleva sentimientos de culpabilidad, mala conciencia, inquietud y falta de confianza en sí mismos como padres. Por ello, opinan que puede ser contraproducente hablar de las consecuencias de la violencia al inicio de las entrevistas. Prefieren esperar a que sean los propios padres quienes saquen el tema a través de una palabra o un pensamiento. Entonces, sí les corresponde y participan en la preocupación y dan su aprobación, ya que han visto también esta dimensión. La experiencia les ha enseñado que la mayoría de los padres toman ellos mismos la iniciativa de hablar de la situación de los niños cuando se sienten seguros haciéndolo. 
Es, en otras palabras, un proceso largo, con pequeños pasos, donde los temas difíciles se exploran conjuntamente. De este modo, el punto de partida es la vivencia propia de los padres, para después intentar ampliar la perspectiva a nuevas estrategias de resolución o alternativas a la violencia.

Otra experiencia, que quiero resaltar aquí, es el trabajo con las familias de otra etnia. El trabajo con estas familias ha sido dirigido más hacia soluciones prácticas, con información sobre recursos de ayuda y derechos sociales. Los que trabajan con ellos dicen que "nuestra cultura de reflexión aparece para muchos como una manera extraña de acercarse al tema de la violencia". Que las diferencias culturales, en cuanto a la actitud ante los problemas, requiere una conciencia importante para trabajar con los conocimientos de la cultura y la comprensión de las actuaciones. Un ejemplo es el de una madre que decía: "vamos a hacer algo agradable y dar un paseo. Hablar de lo doloroso es doble doloroso".

La manera de discutir este tema en el informe enseña que el proyecto ha sido flexible en cuanto a variación y diferencias. No dicen que las familias de otra etnia se adapten al proyecto, sino que consideran un reto para el proyecto el "adaptarse a". Aquí lo que se discute es la importancia de poder salir al encuentro con distintos tipos de necesidades en las familias.

\section{REFLEXIONES SOBRE EL TEXTO.}

Ahora, cuando reflexiono sobre el texto con las gafas de la filosofía de la práctica, tengo que precisar que el proyecto nunca tuvo esta tradición filosófica como marco de referencia. Por ello, podríamos decir que leo el texto de nuevo y lo utilizo como una caso para mi propio propósito. Encuentro que el informe es interesante porque expone y trasmite muchas experiencias concretas.

El proyecto deja apertura a la base ética y al fundamento profesional para que los lectores puedan opinar en cuanto a la base que se ha utilizado para el trabajo. El proyecto pone énfasis en la actitud exenta de juicios y de que debe de haber un espacio abierto para todos los miembros de la familias y sus perspectivas en el diálogo con ellos. La ética se encuentra integrada en lo profesional y guía la actividad de ésta. No tenemos, sin embargo, acceso a las consideraciones éticas relacionadas con la situación concreta.

El informe lleva a muchas situaciones y hechos concretos que muestran lo que ven los agentes de ayuda, sus consideraciones y sus razones. Podemos entender el conocimiento práctico o habilidad como una 
forma de ser concientes. La vista se centra en lo que estamos acostumbrados a ver y el juicio expresa el conocimiento que tenemos de la situación. Aprender a ver trata de la conciencia y de los conocimientos y la habilidad de tomar decisiones. Lo que vemos y cómo lo enfocamos y enmarcamos la situación depende de nuestra comprensión, experiencia y habilidad. Cuando el proyecto va a establecer contacto con una nueva familia, se observa primero la inseguridad de la familia y los agentes de ayuda se adaptan a esta situación, haciendo que la familia sea la primera en decidir cuándo y dónde se van a encontrar con ellos. Deciden enfocar en la inseguridad de la familia para encontrarse con los agentes de ayuda y no sobre la dramática y la violencia. Experimentan que este camino es viable con estas familias, que, a menudo, se retraen del contacto tanto con los agentes de ayudacomo con los profesionales y la policía.

El proyecto describe en varias ocasiones con mucha claridad y concreción lo que hacen y cómo. El ejemplo más claro es cuando hablan con la madre y los niños, cuando discuten cómo deben formularse las preguntas para abrir la comunicación con la familia. Podemos participar en lo que ven y lo que hacen. Aquí transmiten que, si se pregunta al padre por el porqué pegó a su mujer, éste puede entenderlo como una denuncia hacia él y cerrar el diálogo. Lo que intentan es hacer preguntas que puedan abrir un diálogo y ampliar la comprensión de lo que ha pasado realmente. También reflexionan sobre la importancia de que el padre se dé cuenta de que observan y valoran otros valores de él, no sólo el lado violento. Todo ello se adapta a la situación. Aquí nos explican lo que hacen, pero no se observa ningún ejemplo de lo que conllevaría el hecho de hacer preguntas abiertas en situaciones concretas.

Un lector experimentado puede, sin embargo, reconocer en el texto la habilidad profesional. Puede analizar y vivenciar la base de las consideraciones que se visualizan en la descripción. De este modo, se puede discutir y criticar lo que se observa. El lector puede reflexionar sobre lo que se reconoce, lo que es nuevo y lo que quiere llevar consigo para utilizarlo en la práctica.

El proyecto trasmite de este modo mucho de lo que suelen hacer, pero el texto no nos enseña lo que se caracteriza en la filosofía de la práctica, es decir, la fluctuación entre lo general y lo específico o concreto. No participamos en las excepciones y las consideraciones tomadas en las situaciones difíciles. Cuando dicen que quieren encontrarse con cada familia como una familia especial, únicamente nos dejan una visión limitada de lo que ello significa en el trabajo profesional.

La descripción de cómo actúan en las familias de diferente etnia abre, sin embargo, a análisis de cómo intentan escuchar y ser abiertos a la perspectiva que el otro trasmita. Cuando la madre desea ir de 
paseo, antes que hablar de lo doloroso, ello se respeta. Otras veces, la perspectiva del otro tiene que ser valorada contra la comprensión del agente de ayuda, como cuando deciden hablar con los niños en el caso de que la madre exprese signos de ansiedad.

La filosofía de la práctica apunta a la diversidad de las situaciones y la necesidad de profundizar en ellas, explorar en las igualdades y las diferencias y enseñar los dilemas éticos y situaciones que retan a la comprensión.

\section{LA INVESTIGACIÓN SOBRE LA PRÁCTICA COMO DIÁ- LOGO ENTRE EL INVESTIGADOR Y EL PROFESIONAL.}

Lo específico de la filosofía de la práctica es que apunta hacia la actuación. El propósito de reflexionar es llegar a tener más sabiduría y hacer las cosas mejor. El conocimiento profundo debe mejorar la habilidad de hacer importantes distinciones y elecciones de la actuación. De este modo es una actividad para los que tienen que ejecutar, más que para el investigador y los informes de éste.

El método de la filosofía de la práctica es la reflexión. Esas reflexiones pueden realizarse en forma de diálogo (diálogo colectivo) entre el investigador y el profesional, donde este último relata situaciones concretas (Erstad 2000). A través de este proceso se pueden extraer la diversidad, los rasgos típicos y problemas de una situación. Es un proceso de investigación conjunta que requiere mucho diálogo entre los investigadores y los profesionales.

¿Cómo podría la filosofía de la práctica habernos ayudado para seguir a investigar sobre las experiencias en el proyecto? Una pregunta básica es sobre el conocimiento del "cuándo", es decir, cuándo es sabio actuar de una manera u otra, no para establecer una norma de actuación, sino más bien para analizar la actuación a través de ejemplos concretos para profundizar en la comprensión. Una manera de poder enseñar diferencias es investigar en los dilemas. Cuando se encuentra el profesional con importantes dificultades y cuando se reta la comprensión propia o los límites en el trabajo. Dicho de otra manera y con relevancia al proyecto. Cuando el profesional ha utilizado el acercamiento "suave" y las entrevistas de conocimiento, ¿no tuvo buen resultado? ¿Cuándo se encuentra retada la actitud exenta de juicios del profesional? ¿Qué significa en situaciones concretas que se ha enfocado en los niños? Cuando dicen que puede ser contraproducente hablar en las entrevistas del daño que produce en los niños la situaciones de violencia, antes de que los padres están preparados para ello. Nos podemos preguntar si la actitud del profesional ha sido retada cuando 
había razones de fuerte preocupación por los niños. ¿Las experiencias les han llevado a pensar que deberían haber actuado diferente en situaciones así?

En nuestras entrevistas tocamos este tipo de cosas. ¿Cuándo fueron puestas a prueba las actitudes exentas de juicio de los profesionales? ¿Cuáles son los dilemas de tener que relacionarse con la víctima y con el que ha hecho uso de la violencia?

Uno de los trabajadores sociales nos cuenta:

Hay una familia que recuerdo bien. La madre fue víctima varias veces de violencia por parte del marido. Una vez se le veía especialmente mal, tenía hematomas y arañazos en la cara, el brazo estaba enyesado y tenía rota una costilla. Fue a visitarme la familia para que hablara con el padre sobre lo que había pasado.

La mujer estaba en la cocina. Cuando le pregunté al padre qué había hecho, dijo que él no había hecho nada. Le pregunté varias veces y de diferentes maneras. No..., a lo mejor la había arañado un poco en la cara, nada más. Y la costilla rota, pregunté. No..., de esto él no podía decir nada. Sentía que el aire estaba "pesado", impenetrable, en la habitación. ¿Cómo llegar a este hombre? Me sentía con rabia y desesperación. Cuando me fui de allí, pensé que no podía actuar en esta situación. Pasaron varios dias hasta que pude hablar con él por teléfono.

Este ejemplo habla de por sí sobre la dramática, los retos emocionales y los dilemas éticos en el trabajo. Lo que debemos añadir es que el proyecto ha registrado muchos cambios positivos en las relaciones familiares. ${ }^{2}$ Algunas mujeres han podido romper una relación destructiva. Se ha creado un espacio entre los cónyuges. El hechos de que el padre es sujeto de un seguimiento de profesionales parece que da más espacio a la madre para cuidar de su propia situación.

Investigar en la vida "interna" del profesional requiere confianza entre el investigador y el profesional. Esta manera de trabajar conjuntamente requiere tiempo para conocerse y realizar claros acuerdos para este trabajo conjunto. De esta manera, se abre la posibilidad para que los participantes se atrevan a abrirse y a compartir también las experiencias problemáticas y a sentir confianza de que ello se recibirá de una manera éticamente correcta. Es un reto para la actitud ética del investigador, para sortear lo que pertenece a la entrevista y lo que se puede publicar. El investigador debe de ser digno de la confianza que le prestan los profesionales.

2 No entro aquí a hablar de resultados del trabajo. 
El rol del investigador se puede semejar (Janik, 1996) con el rol del entrenador, uno que se encuentra un poco fuera, hace preguntas, aporta buenos análisis y pone las cosas en su contexto. El cometido específico del investigador y su interés principal se encuentran en utilizar el material para profundizar más y conseguir que lo implícito sea explícito y en descubrir las condiciones básicas para la actividad..

Cuando se trabaja con relatos que se cuentan en pasado, a menudo da la impresión de que el reconocimiento se encuentra implícito. La manera de contar el relato también puede participar en el cierre de la comprensión. En una investigación sistemática de la situación es un reto conseguir estimular a la sorpresa. Utilizando literatura, arte, ética o historia de las ideas, se puede conseguir la apertura para la reflexión y la perspectiva. Josefson (1991) sugiere el uso del arte y la poesía como vehículo para la comprensión interna y el redescubrimiento en los profesionales. Haciendo referencia a Landquist:

"La expresión artística es única y tiene su significado propio. La expresión poética nos reaviva imágenes según nuestra experiencia. De este modo el arte sale de sí mismo que por esta razón reclama ser universal, independiente del tiempo y del espacio." (Landquist, 1920).

Porque la reflexión sistemática sobre la práctica apunta a la acción, esta actividad sirve también como una actividad en los programas postgrado para los profesionales. Esta actividad tomará la forma de enseñanza para la investigación.

Pienso que con esto he podido mostrar que la filosofía de la práctica contiene un potencial para el desarrollo de experiencias prácticas y ofrece una aportación para el desarrollo de los conocimientos, donde los conocimientos prácticos y teóricos pueden complementarse e enriquecerse mutuamente.

\section{BIBLIOGRAFÍA.}

ARISTOTELES ETIKK: Et hovedverk i Aristoteles filosofi, også kalt "Den

Nikomakiske etikk". Oversatt og med innledning av Anfinn Stigen. Andre utgave 1996. Gyldendal.

ANDERSON, H. og GOOLISHIAN, H. (1992): Från påverkan til medverkan.

Stockholm : Mareld, 1992.

CULLBERG, J. (1991): Mennesker i krise og utvikling. Aschehoug. Oslo.

ERSTAD, I.H. (2000): Erfaringskunnskap og fortellinger i barnevernet.

Prosjektbeskrivelse NFR.

ERSTAD, I.H. (2000): Conocimientos basados en la experiencia y relatos del 
campo de trabajo social con menores.

Den stille volden -Et prosjekt ved Barnevernvakten. Barne- og familieetaten. Oslo kommune.

JANIK, J. (1996): Kunskapsbegreppet i praktisk filosofi. Brutus Östlings Bokförlag Symposion. Stockholm/Stehag.

LANDQUIST, J. (1920): Människokunskap. Studie över den historiska och den konstnärliga kunskapen. Natur og kultur. Stockholm.

MOLANDER, B. (1993): Kunskap i handling. Göteborg: Bokförlaget Daidalos. JOSEFSON, I. (1991): Kunskapens former. Det reflekterade yrkeskunnandet. Carlsons.

WITTGENSTEIN, L. (1981): Om visshet. Lund. Doxa. 1981. 